\title{
Pembinaan Kemandirian Ibu Dalam Perawatan Metode Kangguru (PMK) Terhadap Peningkatan Suhu Tubuh Pada BBLR Di Ruang NICU RSUD Bima
}

\author{
Nasrullah $^{1(C A)}$ \\ ${ }^{1(C A)}$ Mahasiswa Program Studi Magister Kesehatan Fakultas Kesehatan Universitas Qamarul Huda \\ Badaruddin Jln. H. Badruddin Bagu - Pringgarata - Lombok Tengah \\ e-mail: nsnasrullah2@gmail.com
}

\begin{abstract}
The Kangaroo Method is an early treatment method with a skin-to-skin touch between mother and newborn in a position like Kangaroo. With this method is able to meet the basic needs of premature newborns or low birth weight by providing situations and conditions similar to the mother's womb. LBW infants tend to experience a decrease in body temperature (hypothermia), LBW infants who have experienced hypothermia can have clinical effects, namely decreased oxygen pressure occurs hypoglycemia, increased oxygen consumption, increased calorie reserves, slow weight gain, weight loss, there is sclerema, increased mortality baby, blood clotting factors can occur. For the prevention of hypothermia in LBW can be done in a very simple and easy way and requires a practical method that is economically quite efficient and effective. This research is a quantitative research with pre-experimental research type without comparison groups. The research design used was a Quasi Experiment with "One Group Pre-Test-Post Test Design", researchers tested changes that occurred after an experiment or intervention. The results of the measurement of pre and post intervention were performed Wilcoxon test statistical test which is a statistical test to find out two matching data or one data were examined twice. with 42 respondents. The Wilcoxon T statistical test results also support the data in the table above, where from the test results obtained $\mathrm{P}$ value $=0.000<0.05$ with a confidence level of $95 \%$. This means that there is the effect of Kangaroo Care Method (PMK) on increasing body temperature at LBW in Nicu Room Bima Hospital. The results of this study can be used as input for management in the Bima Regional Hospital, especially in the NICU room on the quality of nursing services and also further develop the care of the Kangaroo Method (PMK) on increasing body temperature in LBW in order to improve the degree of maternal and child health
\end{abstract}

\section{Keywords: Body Temperature, LBW, Kangaroo Method}

\begin{abstract}
ABSTRAK
Metode Kangguru adalah metode perawatan dini dengan sentuhan kulit ke kulit antara ibu dan bayi baru lahir dalam posisi seperti Kangguru. Dengan metode ini mampu memenuhi kebutuhan asasi bayi baru lahir prematur atau Berat lahir rendah dengan menyediakan situasi dan kondisi yang mirip dengan rahim ibu. Bayi BBLR cenderung mengalami penurunan suhu tubuh (hipotermia), bayi BBLR yang telah mengalami hipotermi dapat mempunyai efek klinis yaitu penurunan tekanan oksigen terjadi hipoglisemia, peningkatan konsumsi oksigen, peningkatan cadangan kalori, kenaikan berat badan lambat, penurunan berat badan, terdapat sklerema, peningkatan kematian bayi,dapat terjadi faktor pembekuan darah. Untuk pencegahan hipotermia pada BBLR bisa dilakukan dengan cara yang sangat sederhana dan mudah serta diperlukan suatu metode praktis yang secara ekonomis cukup efisien dan efektif. Penelitian ini merupakan penelitian kuantitatif dengan jenis penelitian pra eksperimen tanpa kelompok pembanding. Rancangan penelitian yang digunakan adalah Quasi Ekperimen dengan "One Group Pre test-Post test Design", peneliti menguji perubahan-perubahan yang terjadi setelah adanya eksperimen atau intervensi.Selisih hasil pengukuran pre dan post intervensi dilakukan uji statistik wilcoxon test yang merupakan uji statistik untuk mengetahui dua data berpasanagn atau satu data diteliti dua kali.dengan jumlah responden 42 orang. Hasil uji statistik $T$ Wilcoxon Test juga mendukung data pada tabel diatas, dimana dari hasil uji diperoleh $P$ value $=0.000<0.05$ dengan tingkat kepercayaan $95 \%$. Artinya ada
\end{abstract}


Pengaruh Perawatan Metode Kangguru (PMK) Terhadap peningkatan suhu tubuh pada BBLR di Ruang Nicu RSUD Bima. Hasil penelitian ini dapat dijadikan masukan bagi manajemen di RSUD Bima khususnya di ruang NICU terhadap mutu pelayanan keperawatannya dan juga lebih mengembangkan perawatan Metode Kangguru (PMK) Terhadap peningkatan suhu tubuh pada BBLR dalam rangka meningkatkan derajat kesehatan ibu dan anak.

\section{Kata Kunci : Suhu Tubuh, BBLR, Metode Kangguru}

\section{PENDAHULUAN}

Metode Kangguru adalah metode perawatan dini dengan sentuhan kulit ke kulit antara ibu dan bayi baru lahir dalam posisi seperti Kangguru. Dengan metode ini mampu memenuhi kebutuhan asasi bayi baru lahir prematur atau Berat lahir rendah dengan menyediakan situasi dan kondisi yang mirip dengan rahim ibu. (Henderson, dlm Puji dkk, 2009). Bayi BBLR cenderung mengalami penurunan suhu tubuh (hipotermia), bayi BBLR yang telah mengalami hipotermi dapat mempunyai efek klinis yaitu penurunan tekanan oksigen terjadi hipoglisemia, peningkatan konsumsi oksigen, peningkatan cadangan kalori, kenaikan berat badan lambat, penurunan berat badan, terdapat sklerema, peningkatan kematian bayi,dapat terjadi faktor pembekuan darah.

Penurunan suhu pada bayi tersebut terjadi pada menit-menit ke 10-20 setelah kelahiran. Hal ini disebabkan oleh ketidakmampuan bayi untuk menghasilkan panas yang cukup untuk mengimbangi hilangnya panas saat kelahiran. Selain itu suhu dingin dan luar permukaan yang lebih besar dibandingkan dengan tubuhnya yang kecil serta kepalanya yang secara proporsional lebih besar, juga bisa menyebabkan turunnya suhu pada bayi. (Aris, 2009).

Adapun dampak atau konsekuensi dari hipothermia biasanya sangat parah, bayi berat badan lahir rendah yang hipotermia akan menderita hipoglycemia (gula darah rendah) serta asidosis metabolis, sebab mereka akan mencoba untuk menghasilkan panas guna mempertahankan suhu tubuhnya. Bila terjadi hipoglycemia berat akan menyebabkan gagal kegawatan pernafasan serta penggumpalan darah yang abnormal. BBL yang menderita cedera dingin dan hipothermia akan menghadapi resiko yang lebih tinggi lagi terkena infeksi, penguningan (jaundice), serta pulmonaria hemorrhage (perdarahan paru-paru). BBL dengan hipothermia akan lebih besar kemungkinannya meninggal disbanding dengan bayi baru lahir yang tidak mengalami hipothermia. (WHO, dlm Aris 2009)

Berdasarkan Survey Demografi Kesehatan Indonesia (SDKI) tahun 2007,kematian bayi di Indonesia mencapai $34 / 1000 \mathrm{KH}$, sekitar $56 \%$ kematian bayi terjadi pada periode sangat dini (neonatal), sementara target Millennium Development Goals (MDG) pada tahun 2015 menurunkan angka kematian bayi menjadi 23/1000 kelahiran hidup. ${ }^{2}$ Menurut WHO dalam State of the world's mother 2016 bahwa 27\% kematian neonatal disebabkan oleh Bayi Berat Lahir Rendah (BBLR). Indonesia sebagai negara berkembang, kematian dan kesakitan oleh karena BBLR mencapai angka yang cukup tinggi yaitu 14\%. Riset Kesehatan Dasar (Riskesdas, 2019)

RSUD Bima sebagai rumah sakit rujukan di Wilayah Kota Bima dan Kabupaten Bima, didapatkan data pada tahun 2016 jumlah kejadian BBLR sebanyak 251 orang, pada tahun 2017 didapatkan data sebanyak 289 orang dan pada tahun 2018 periode Januari - Mei jumlah kejadian BBLR sebanyak 178 
orang.dengan pendistribusian suhu tubuh bayi adalah bayi dengan suhu $<36^{\circ} \mathrm{c}$ (hipotermia) 42 bayi, suhu antara 36,5 - 37,5 $5^{\circ}$ (normal) 132 bayisuhu >37, $5^{\circ} \mathrm{c}$ (hipertermia) 4 bayi. (Data Rekam Medik RSUD Bima, 2019)

Untuk pencegahan hipotermia pada BBLR bisa dilakukan dengan cara yang sangat sederhana dan mudah serta diperlukan suatu metode praktis yang secara ekonomis cukup efisien dan efektif. Ditemukannya perawatan metode Kangguru (PMK) telah terjadi revolusi pada perawatan BBLR mudah dikerjakan oleh setiap orang yaitu menghangatkan bayi melalui panas tubuh ibu. Bayi diletakkan telungkup di dada ibu agar terjadi kontak kulit ke kulit antara ibu dan bayi secara langsung, yang biasanya lazim disebut dengan "Metode Kangguru”, menghangatkan bayi dalam inkubator, bayi dikeringkan segera setelah lahir, ataupun dibungkus di dalam kain yang hangat. (Sarwono, 2010)

\section{METODE}

Penelitian ini merupakan penelitian kuantitatif dengan jenis penelitian pra eksperimen tanpa kelompok pembanding. Rancangan penelitian yang digunakan adalah Quasi Ekperimen dengan "One Group Pre test-Post test Design”, analisis data menggunakan uji Wilcoxon dengan bantuan program komputer.

\section{HASIL}

1. Karakteristik responden

Tabel 1. Karakteristik Responden di Ruang NICU RSUD Bima (n=42)

\begin{tabular}{|c|c|c|c|}
\hline No & Karakteristik & Frekwensi & $\%$ \\
\hline 1. & $\begin{array}{l}\text { Golongan Umur: } \\
-\quad 1-10 \text { hari } \\
-\quad 11-20 \text { hari } \\
-\quad 21-30 \text { hari }\end{array}$ & $\begin{array}{l}13 \\
18 \\
11 \\
\end{array}$ & $\begin{array}{c}31 \\
42.9 \\
26.2\end{array}$ \\
\hline 2. & \begin{tabular}{ll}
\multicolumn{2}{l}{ Jenis Kelamin } \\
$-\quad$ Laki-Laki \\
$-\quad$ Perempuan
\end{tabular} & $\begin{array}{l}18 \\
24\end{array}$ & $\begin{array}{l}42.9 \\
57.1\end{array}$ \\
\hline
\end{tabular}

Berdasarkan tabel 1 didapatkan frekuensi responden berdasarkan golongan umur bayi mayoritas berusia 11 - 20 hari (42.9\%), sedangkan berdasarkan jenis kelamin mayoritas berjenis kelamin perempuan $(57,1 \%)$.

2. Kemandirian Ibu Dalam Perawatan Metode Kangguru

Tabel 2 Analisa Pembinaan kemandirian ibu dalam perawatan metode kangguru (PMK) terhadap peningkatan suhu tubuh pada BBLR diruang NICU RSUD Bima Tahun $2019(\mathrm{n}=42)$

\begin{tabular}{lcccc}
\hline Suhu Tubuh BBLR & \multicolumn{2}{c}{ Sebelum } & \multicolumn{2}{c}{ Sesudah } \\
\cline { 2 - 5 } & Frekwensi & $\%$ & Frekwensi & $\%$ \\
\hline
\end{tabular}




\begin{tabular}{|c|c|c|c|c|}
\hline Hipotermi & 42 & $100 \%$ & 19 & $45.2 \%$ \\
\hline \multirow[t]{2}{*}{ Normal } & 0 & 0 & 23 & $54.8 \%$ \\
\hline & Uji Wilc & $p=0,00$ & & \\
\hline
\end{tabular}

Tabel 2 menunjukkan bahwa, secara kuantitas suhu tubuh bayi Hipotermi sebelum dilakukan perawatan metode Kangguru (PMK) berjumlah 42 bayi dengan persentase $100 \%$, dan setelah dilakukan perawatan metode Kangguru (PMK) terjadi berubah menjadi berjumlah 23 bayi (54.8\%) dengan suhu tubuh Normal, dan 19 bayi (45.2\%) dengan suhu tubuh Hipotermi. Hasil uji statistik $T$ Wilcoxon Test juga mendukung data pada tabel diatas, dimana dari hasil uji diperoleh $P$ value $=$ $0.000<0.05$ dengan tingkat kepercayaan $95 \%$. Artinya ada Pengaruh Pembinaan kemandirian ibu dalam perawatan metode kangguru (PMK) terhadap peningkatan suhu tubuh pada BBLR diruang NICU RSUD Bima Tahun 2019.

\section{PEMBAHASAN}

Hasil uji statistik $T$ Wilcoxon Test juga mendukung data pada tabel diatas, dimana dari hasil uji diperoleh $P$ value $=0.000<0.05$ dengan tingkat kepercayaan $95 \%$. Artinya Ho ditolak dan $\mathrm{H} 1$ diterima ada Pengaruh Perawatan Metode Kangguru (PMK) Terhadap peningkatan suhu tubuh pada BBLR di Ruang Nicu RSUD Bima. Perawatan BBLR memerlukan tindakan yang segera dan intensif sesuai dengan kondisi bayi untuk menghindari terjadinya komplikasi terutama hipotermi. Pencegahan hipotermi pada bayi dapat dilakuan dengan cara memasukan bayi kedalam inkubator atau melakukan perawatan bayi dengan metode kangguru. Penggunaan inkubator lebih mudah, namun penggunaan alat ini masih sangat dipengaruhi dengan keterbatasan inkubator dan pasokan arus listrik. Sedangkan metode kanguru dapat dilakukan dimana saja dan kapan saja selama ibu dalam keadaan sehat. Metode kanguru adalah cara merawat bayi secara alami seperti perawatan bayi kanguru dalam kantung indungnya, sehingga bayi mendapat kontak langsung antara kulit bayi dan ibunya secara terus menerus serta pancaran panas udara didalam kantung bayi tersebut, sehingga bayi terhinda dari kedinginan/hipotermia (Usman dalam PERINASIA 2001)

Penurunan suhu pada bayi tersebut terjadi pada menit-menit ke 10-20 setelah kelahiran. Hal ini disebabkan oleh ketidakmampuan bayi untuk menghasilkan panas yang cukup untuk mengimbangi hilangnya panas saat kelahiran. Selain itu suhu dingin dan luar permukaan yang lebih besar dibandingkan dengan tubuhnya yang kecil serta kepalanya yang secara proporsional lebih besar, juga bisa menyebabkan turunnya suhu pada bayi. (WHO, 2006). Adapun mekanisme atau proses penurunan suhu pada BBL, yaitu segera setelah dilahirkan, suhu BBL akan turun. Bayi yang masih basah bisa kehilangan panas cukup banyak untuk membuat suhu tubuhnya turun sampai sebanyak 2$4{ }^{\mathrm{O}} \mathrm{C}\left(3,6-7,2^{\circ} \mathrm{C}\right)$. Karena dalam keadaan basah, maka bayi tersebut akan kehilangan sebagian besar panas tubuhnya melalui penguapan (evaporasi) dari permukaan kulit yang basah, persentuhan dengan benda-benda yang dingin (konduksi), persentuhan dengan udara dingin (konveksi), atau persentuhan dengan benda-benda yang bersuhu lebih rendah di sekitarnya (radiasi). (WHO, 2008). 
Untuk pencegahan hipothermia pada BBL bisa dilakukan dengan cara yang sangat sederhana dan mudah dikerjakan oleh setiap orang yaitu menghangatkan bayi melalui panas tubuh ibu. Bayi diletakkan telungkup di dada ibu agar terjadi kontak kulit ke kulit antara ibu dan bayi secara langsung, yang biasanya lazim disebut dengan "Metode Kanguru", menghangatkan bayi dalam inkubator, bayi dikeringkan segera setelah lahir, ataupun dibungkus di dalam kain yang hangat. (Sarwono, 2007).

\section{KESIMPULAN}

Berdasarkan hasil analisis data dan pembahasan hasil penelitian maka dapat diambil kesimpulan sebagai berikut :

1. Suhu tubuh bayi Hipotermi sebelum dilakukan perawatan metode Kangguru (PMK) berjumlah 42 bayi dengan persentase $100 \%$,

2. Setelah dilakukan perawatan metode Kangguru (PMK) terjadi berubah menjadi berjumlah 23 bayi $(54.8 \%$ ) dengan suhu tubuh Normal, dan 19 bayi (45.2\%) dengan suhu tubuh Hipotermi.

3. Ada Pengaruh Perawatan Metode Kangguru (PMK) Terhadap peningkatan suhu tubuh pada BBLR di Ruang Nicu RSUD Bima

\section{DAFTAR PUSTAKA}

Arikunto, S. (2006). Prosedur Penelitian. Edisi Revisi III. Rineka Cipta Yogyakarta.

Aris Puji (2007) PENGARUH PENERAPAN METODE KANGURU TERHADAP PENINGKATAN SUHU BAYI BARU LAHIR (Di BPS. Kasih Ibu Ny. Soenarlin Jatirogo-Tuban).

Amin Hn, Hardi. 2015. Aplikasi Asuhan Keperewatan Berdasarkan Diagnosa Medis NIC-NOC Jilid I. Mediaction. Yogyakarta

Data Rekam Medik RSUD Bima, 2019

Dyah Puji Astuti, dkk (2009). PENGARUH PENERAPAN METODE KANGURU DENGAN PENINGKATAN BERAT BADAN BAYI BARU LAHIR RENDAH (BBLR) DI RUMAH SAKIT PKU MUHAMMADIYAH GOMBONG.

Effendy Nasrul (2005). Proses Keperawatan. EGC. Jakarta.

Hidayat, Aa (2009). Metode Penelitian keperawatan dan teknik analisa Data Jakarta. Salemba Medika

Manuaba IBG. (2008). Ilmu Kebidanan, Penyakit Kandungan dan Keluarga Berencana Untuk Pendidikan Bidan. Jakarta: EGC, hal:128.

Nelson (2009). Ilmu Kesehatan Anak. EGC. Jakarta.

Nursalam. (2003). Konsep \& Penerapan Metodologi Penelitian Ilmu Kesehatan Pedoman Skripsi, Tesis, dan Instrumen Penelitian Keperawatan. Jakarta: Salemba Medika

Nursalam. (2001). Konsep \& Penerapan Metodologi Penelitian Ilmu Kesehatan Pedoman Skripsi, Tesis, dan Instrumen Penelitian Keperawatan. Jakarta: Salemba Medika 
Riskesdas (2016). Pedoman Pelayanan Antenatal di Tingkat Pelayanan Dasar Puskesmas. Jakarta: Pusdiknakes

Notoatmodjo, Soekidjo. (2002). Metodologi Penelitian Kesehatan. Edisi Revisi. Jakarta: Rineka Cipta Sugiyono, Eri Wibowo (2007). Statistika Penelitian. Penerbit Alfabeta. Bandung. 